(2)

OPEN ACCESS

EDITADO POR

- Miguel Oliveira, Jr. (UFAL)

- René Almeida (UFS)

REVISADO POR

- Marco Martins (UFSC)

- Jorge de Moraes (USP)

DATAS

- Recebido: 31/01/2020

- Aceito: 22/06/2020

- Publicado: 27/11/2020

COMO CITAR

PIRES, Aline Jéssica. (2020). A

influência da gramática espanhola na

Marcação Diferencial de Objeto no

Português diacrônico. Cadernos de

Linguística, v. 1, n. 2, p. 01-20.

\title{
A INFLUÊNCIA DA GRAMÁTICA ESPANHOLA NA MARCAÇÃOO DIFERENCIAL DE OBJETO NO PORTUGUÊS DIACRÔNICO
}

\author{
Aline Jéssica PIRES (D) $\boldsymbol{\Delta}$ \\ Universidade Estadual de Campinas (UNICAMP)
}

\section{RESUMO}

A Marcação Diferencial de Objeto (MDO) consiste em marcar o objeto direto com uma preposição. Em português, a MDO ocorre apenas com a preposição dativa A. O presente artigo, sob a perspectiva teórica gerativista, examina casos de objetos diretos morfologicamente marcados no português antigo. Nosso principal objetivo é verificar a hipótese bastante difundida sobre a influência espanhola na ocorrência da MDO em português. Para atingir esse objetivo, analisamos textos portugueses de dois corpora selecionados. Investigamos fatores apontados como desencadeadores da MDO (BOSSONG, 1991): os traços semânticos da animacidade, definitude e especificidade. Para confirmar se os casos de MDO encontrados em dados diacrônicos do português foram influenciados pelo espanhol e atestar quando, na história da língua, o fenômeno diminuiu, analisamos dados dos séculos XVI a XIX. Para atestar se a MDO que ocorre no português e no espanhol é a mesma, comparamos dados marcados e não marcados dos séculos XVI e XVII. Os resultados confirmam a hipótese da influência espanhola, embora a distribuição da MDO não seja a mesma no português e no espanhol dos séculos aqui analisados. Em português, os casos de objetos não marcados são mais frequentes que os casos de MDO. 


\section{ABSTRACT}

The Differential Object Marking (DOM) consists of marking the direct object with a preposition. In Portuguese DOM occurs only with the dative preposition A. The present paper, under the Generative theoretical framework, examines cases of morphologically marked direct objects in Old Portuguese. Our main objective is to verify the widespread hypothesis of the Spanish influence on the occurrence of DOM in Portuguese. To achieve this goal, we analyze Portuguese texts from two selected corpora. We investigate factors pointed out as triggers of DOM (BOSSONG, 1991): the semantic features of animacy, definiteness, and specificity. To confirm if the cases of DOM found in diachronic data from Portuguese were influenced by Spanish and attest when, in the history of the language, the phenomenon decreased, we analyzed data from the 16th to the 19th centuries. In other to attest if the DOM that occurs in Portuguese and Spanish are the same, we compare marked and non-marked data from the 16th and the 17th centuries. The results confirm the hypothesis of the Spanish influence, although the distribution of DOM is not the same in the Portuguese and Spanish of the centuries analyzed here. In Portuguese, the cases of non-marked objects are more frequent than the DOM cases.

PALAVRAS-CHAVE

Marcação Diferencial de Objeto; Preposição A; Linguística Diacrônica.

\section{KEYWORDS}

Differential Object Marking. Preposition A. Diachronic Linguistics. 


\section{INTRODUÇÃO}

O fenômeno conhecido como Marcação Diferencial de Objeto (doravante MDO) ocorre quando um objeto direto é marcado morfologicamente. A MDO é encontrada normalmente em línguas em que não há marcação morfológica de caso. Propriedades intrínsecas e referenciais do objeto marcado, dentre as quais estão a animacidade, definitude e especificidade favorecem a marcação (BOSSONG, 1991; TORREGO, 1998; entre outros).

De acordo com Bossong (1991), o fenômeno é encontrado em línguas de diferentes famílias. Nas línguas românicas, casos em que um objeto direto é marcado por uma preposição dativa são classificados como instâncias da MDO. Nessas ocorrências, a preposição não seria esperada, pois, como o próprio nome sugere, o complemento direto se liga diretamente ao verbo.

Na maioria das línguas românicas em que ocorre, a MDO é marcada pela preposição "a". Como mostra (1), no português, há casos de variação da preposição; há ainda a preferência pela marcação de "a" com certos DPs, como "Deus" (2b). Por sua vez, o espanhol é uma língua que se caracteriza pela alta frequência do fenômeno, objetos animados são marcados pela preposição "a", como mostra o exemplo em (3).

(1) a. A novela comoveu (a)os espectadores.

(2) a. Amo o Joaquim.

b. Amo a Deus.

(3) El profesor vigila * (a) sus alumnos. $\quad$ (Espanhol)

Pesquisas de diferentes perspectivas teóricas têm fornecido importantes evidências sobre a natureza do fenômeno. Entretanto, a investigação tem se centrado no espanhol, e mais recentemente, no catalão, em algumas variedades do italiano e no romeno (ESCANDELL-VIDAL, 2009; IEMMOLO, 2010; MARDALE, 2015; entre outros).

Apesar de poucos, há estudos que confirmam a existência do fenômeno no português antigo. Além disso, pesquisas que atestam a presença da MDO na sincronia da língua têm sido publicadas. No português atual, o fenômeno se restringe a poucos contextos de ocorrência, como com objetos animados em sentenças comparativas (cf. (4)), coordenadas (cf. (5)) e é opcional com quantificadores [+animados] (cf. (6)) (CYRINO, 2017).

(4) O Pedro ama a Rita como a uma mulher.

(5) Eu vi o menino e ao professor também.

(6) Ele visitou a todos. (todos $=[+$ animado]). 
Estudos sobre o fenômeno no português atestam sua diminuição na história da língua e indicam um aumento da frequência durante os séculos XVI e XVII (RAMOS, 1992; GIBRAIL, 2003; DÖHLA, 2014; PIRES, 2017). Ramos (1992) e Döhla (2014) defendem que o aumento da frequência do fenômeno nesse período foi ocasionado pela criação da União Ibérica (15801640), em que Portugal e Espanha formavam um mesmo reino e, consequentemente, as línguas portuguesa e espanhola ficaram sob intenso contato.

A hipótese sobre a influência espanhola no uso da MDO encontra respaldo em Hills (1920), em que são mencionados diferentes territórios, dentre os quais estão, por exemplo, o sudoeste da França e parte da Itália, em que há ocorrências de objetos diretos marcados. O autor observou uma característica interessante nesses locais: todos sofreram influência espanhola, seja pela proximidade geográfica ou pelo poder político.

No presente trabalho, utilizando dados de corpora de português antigo, verificamos se a presença do MDO no português é resultado do contato com a língua espanhola. Para confirmar se os casos de objetos diretos marcados encontrados em dados diacrônicos do português foram influenciados pela gramática espanhola e para atestar quando, na história da língua, o fenômeno diminuiu, analisamos a presença dos traços semânticos da animacidade, definitude e especificidade em dados dos séculos XVI ao XIX. Com o objetivo de atestar se o fenômeno que ocorre no português e no espanhol é o mesmo, comparamos dados do português dos séculos XVI e XVII, nos quais o objeto direto é marcado pela preposição "a" e casos típicos de objeto direto, ou seja, dados em que o objeto direto não recebe nenhuma marcação. Os resultados de nossa análise indicam que, durante a União lbérica, a frequência da MDO aumentou, no entanto, como mostraremos ao longo do texto, a distribuição do fenômeno não é a mesma no português e no espanhol dos séculos analisados no presente estudo.

O trabalho está dividido da seguinte maneira: na seção a seguir são apresentadas algumas características da MDO; na sequência, a seção 3 é dedicada aos estudos sobre o fenômeno no português; na seção 4, a hipótese da influência espanhola é explicada com mais vagar; a seção 5 é reservada à análise dos dados; na sequência são apresentadas as considerações finais.

\section{A MARCAÇÃO DIFERENCIAL DE OBJETO}

A MDO, segundo Bossong (1984), é encontrada em mais de 250 línguas. O fenômeno é desencadeado por propriedades intrínsecas e referenciais do objeto, que são codificadas em duas escalas: a da animacidade e a da definitude (AISSEN, 2003). Além disso, ambas permitem generalizações sobre a MDO. 
(7) Escala da Animacidade: humano > animado > inanimado.

(8) Escala da Definitude: pronome de primeira/segunda pessoa $>$ pronome de terceira pessoa > nome próprio > DP definido > DP indefinido específico > DP não-específico.

De acordo com as escalas, objetos diretos que ocupam as posições mais altas seriam marcados, por outro lado, os que ocupam as posições mais baixas seriam opcionalmente marcados ou não seriam marcados. As línguas que apresentam o fenômeno teriam diferentes pontos de corte na escala, os itens à esquerda seriam marcados, enquanto os à direita não seriam marcados (ou seriam opcionalmente marcados, a depender da língua).

A seguir, discutimos os traços semânticos da animacidade, definitude e especificidade mencionados acima.

\subsection{OS TRAÇOS SEMÂNTICOS}

A animacidade é um traço semântico que descreve uma propriedade do objeto. Cyrino (2018) observa que este traço é relevante para vários fenômenos sintáticos, como MDO, leísmo e PCC. A pesquisadora defende que a escala da animacidade apresentada acima está codificada na hierarquia sintática. Entretanto, Cyrino acredita que essas escalas não são adequadas: "o poder explanatório de tais hierarquias é duvidoso dentro de uma perspectiva formal, pois não está claro qual seu papel dentro do quadro teórico. Seriam efeitos da Gramática Universal, ou derivariam de princípios cognitivos independentes?” (2018, p. 231). A autora propõe então que a hierarquia DP [+animado] > DP [-animado] representa a posição dos DPs na árvore sintática.

Para Cyrino, há um núcleo funcional F[Pessoa] localizado entre IP e V. Os DPs animados estão mais acima na árvore, pois são atraídos pelos traços EPP desse núcleo funcional, o que faz com que os DPs inanimados permaneçam in situ.

A escala da definitude mostrada acima (cf. (8)) reúne tanto características que dependem da definitude quanto da especificidade. Isso acontece porque os dois traços dizem respeito a propriedades referenciais do objeto. Farkas (2002) questiona a hierarquia da escala em (8), afinal, por que nomes próprios e pronomes estão em uma posição mais alta que DPs definidos? Para responder a essa questão é necessário definir os conceitos.

Brasoveanu e Farkas (2016) adotam que os definidos seguem algum requerimento especial enquanto os indefinidos não o fazem. Esse requerimento pode estar relacionado à familiaridade ou à unicidade (uniqueness). Com relação ao primeiro, os definidos são aqueles já mencionados no discurso, por outro lado, os indefinidos são os ainda não mencionados, ou seja, são novos. Sobre a unicidade, os definidos são os únicos em uma classe possível de objetos e os indefinidos são aqueles que não são únicos. Isto é, a 
definitude depende de uma restrição, os que a obedecem são os definidos e os que não o fazem, são os indefinidos.

Como coloca Farkas (2002), a ideia de a definitude estar relacionada à unicidade, atualmente, tem sido mais adotada que a ideia de familiaridade. De acordo com a visão de definitude de Brasoveanu e Farkas (2016), os DPs definidos requerem uma referência fixa, que não é solicitada pelos indefinidos. Os pesquisadores acrescentam que os indefinidos não impõem nenhuma restrição interpretativa especial.

Coppock e Beaver (2015) diferenciam a definitude de outro conceito, a determinação (determinacy). A definitude, no inglês, é uma categoria morfológica que marca a pressuposição de unicidade, isto é, não implica a existência do referente, apenas pressupõe que existe um único referente (seja um indivíduo ou um grupo delimitado). Por sua vez, a determinação denota um indivíduo em um dado contexto.

Sobre a especificidade, Farkas e Brasoveanu (2013) afirmam que, nas discussões sobre esse traço semântico, a noção de alternativa tem ganhado espaço, mas ainda assim não há consenso sobre a definição do termo. Os autores adotam que alternativa é o conjunto de valores do NP que são atribuídos pelo determinante do DP, esses valores dependem do contexto linguístico e extra-linguístico. Farkas e Brasoveanu dividem o determinante em dois tipos: pró-variação e anti-variação. O primeiro impõe uma restrição que leva à relativa variabilidade do referente; já o determinante anti-variação restringe a relativa estabilidade do referente. Os DPs específicos são aqueles encabeçados por determinantes anti-variação, ou seja, a especificidade limita a variação do referente.

Neste trabalho, foi adotada a hierarquia proposta por Cyrino, então, diferenciamos os objetos entre animados e inanimados, e não distinguimos aqueles que eram humanos, como propõe a escala da animacidade mostrada em (7). Além disso, na análise dos dados, foi considerado que DPs definidos são aqueles que pressupõem a existência de uma referência fixa, já os específicos são aqueles que não apresentam variabilidade na referência, ou seja, denotam um referente único. A seção 3 abaixo é dedicada à apresentação das características da MDO no português.

\section{A MARCAÇÃO DIFERENCIAL DE OBJETO NA HISTÓRIA DO PORTUGUÊS}

Cyrino (2017) aponta que a MDO no português se restringe a objetos [+animados] e que o fenômeno é utilizado em estruturas de coordenação. Em (9a), por exemplo, a ausência da preposição permite a leitura de que o professor também viu o menino. Já em (5), retomado em (9b), a preposição restringe a leitura: o sujeito viu ambos os objetos, o menino e o 
professor. A autora ressalta, também, a opcionalidade da marcação diferencial com sintagmas quantificados [+animados] (cf. (10)).

(9) a. Eu vi o menino e o professor também.

b. Eu vi o menino e ao professor também.

(10) a. Ele visitou (a) alguns homens.

b. ${ }^{\star}$ Eu vi a algumas escolas.

Cyrino e Ordoñez (2016) salientam que, em sentenças comparativas, a presença da MDO pode levar a diferentes leituras. O objeto não marcado em (11a) leva à leitura de que o Pedro ama a Rita como se ele fosse uma mulher, já em (11b), a marcação da preposição leva a uma interpretação de comparação: o Pedro ama a Rita da mesma maneira que ele ama uma mulher.

(11) a. O Pedro ama a Rita como uma mulher.

b. O Pedro ama a Rita como a uma mulher.

Os estudos sobre a ocorrência da MDO no português, com exceção dos trabalhos de Cyrino e Ordoñez (2016) e Cyrino (2017) citados acima, se concentram na diacronia da língua. Eles revelam que, ao longo da história, a frequência do fenômeno diminuiu consideravelmente e se restringiu a poucos contextos de uso.

Ramos (1992) defende que, no português, a marcação pela preposição "a" funciona como um recurso extra de marcação de caso quando sujeito e objeto são animados. Além disso, as ordens OV e VS, e a estrutura VXO influenciam na marcação diferencial. Em seu estudo, a autora observou, no século XIX, uma queda na frequência de objetos marcados. Essa verificação está relacionada a outras mudanças, como a da ordem OV para a ordem VO, a ordem VS para a SV com verbos transitivos e a mudança na realização do objeto anafórico, isto é, a tendência de o objeto nulo substituir clíticos.

Em sua análise sobre os casos de MDO no português clássico, Gibrail (2003) adota que os objetos desse tipo são PPs que possuem o traço semântico [+específico]. A pesquisadora constata um aumento na frequência da MDO em textos de escritores nascidos na segunda metade do século XVI, sendo que o uso do fenômeno em contextos mais abrangentes é verificado em textos de escritores nascidos na segunda metade do século XVI e no XVII. Contudo, nos escritos de autores nascidos no século XVIII se observa uma queda das ocorrências do fenômeno.

No português antigo, de acordo com Döhla (2014), fatores sintáticos desencadeavam a marcação diferencial, dentre esses estavam a presença de dois objetos diretos marcados simultaneamente - fenômeno chamado pelo autor de paralelização -, a 
deslocação à esquerda e a ordem VSO. Além disso, nesse período, eram marcados os objetos [+animados] e [+definidos].

Ainda segundo o estudo de Döhla, no século XVI, a frequência da MDO dependia da gramática individual do autor. Já no século XVII, há o pico de ocorrências dos casos de MDO, e, diferentemente do século anterior, o fenômeno deixa de ser uma questão de gramáticas individuais dos autores e passa a ser um fenômeno da língua.

Os estudos de Döhla (2014) e Ramos (1992) têm um ponto em comum: ambos destacam que o pico de frequência da MDO observado nos séculos XVI e XVII é consequência do contato do português com o espanhol, o que foi causado pela criação da União Ibérica (15801640), período em que Portugal e Espanha estiveram sob o comando de um mesmo rei. Tal hipótese é investigada neste trabalho. Na seção 4, a seguir, são apresentados com mais vagar alguns dos pontos relevantes para a discussão desse tema.

\section{A HIPÓTESE DA INFLUÊNCIA ESPANHOLA}

Como dito anteriormente, a marcação diferencial de objeto direto ocorre em diversas línguas românicas, sendo que o espanhol é, possivelmente, a língua românica em que mais se destaca, pois os objetos diretos animados são obrigatoriamente marcados. Hills (1920) listou diferentes línguas em que há ocorrências do fenômeno e observou que em todas houve contato com o espanhol, seja pela proximidade geográfica ou pelo poder político. Além disso, mesmo que haja distinções nos contextos de ocorrências, nas línguas românicas, a MDO ocorre frequentemente com pronomes pessoais.

Tais fatores contribuíram para uma hipótese bastante difundida: a MDO seria um fenômeno da língua espanhola e sua ocorrência em outras línguas seria fruto do contato. Entretanto, há estudos que colocam em dúvida essa hipótese, pois atestam na Península lbérica a presença do fenômeno já em latim tardio (PENSADO, 1995). Além disso, no século $X V$, os contextos de ocorrência já se mostravam distintos em algumas línguas românicas, como no espanhol e no português; no primeiro era mais frequente com pronomes pessoais e nomes próprios, por outro lado, no português, a MDO era desencadeada por fatores sintáticos (DÖHLA, 2014).

Havia na época um processo de castelhanização de Portugal, que abarcava desde a língua e a literatura até o estilo de vida.

Entre meados do século XV e fins do século XVII o espanhol serviu como segunda língua para todos os portugueses cultos. Os casamentos de soberanos portugueses com princesas espanholas tiveram como efeito uma certa "castelhanização" da corte. Os sessenta anos de dominação espanhola (1580-1640), que se situam no período mais brilhante do "Século de Ouro", acentuaram esta impregnação linguística. E somente depois de 1640, com a Restauração e a subida ao trono de D. João IV, que se produz uma certa reação anti-espanhola. O bilinguismo, todavia, perdurara até o desaparecimento dos últimos representantes da geração formada antes de 
1640. Assim, durante aproximadamente dois séculos e meio, o espanhol foi em Portugal uma segunda língua de cultura (Teyssier, 2007, p.32).

Para verificar essa hipótese nos casos de objetos marcados diferencialmente, é necessário antes descrever o desenvolvimento do fenômeno na história do espanhol. Na subseção a seguir, são apresentados pontos relevantes para a discussão deste estudo.

\subsection{A MARCAÇÃO DIFERENCIAL DE OBJETO NA HISTÓRIA DO ESPANHOL}

Como dito acima, no espanhol, a preposição "a" é responsável pela MDO. São marcados os objetos animados (cf. (12)), contudo, objetos animados indefinidos levam à opcionalidade da marcação (cf. (13)) (TORREGO, 1999).

(12) Trajeron *(a) Jimena.

'Trouxeram à Jimena'.

(13) Trajeron (a) un amigo con ellos.

'Trouxeram (a) um amigo com eles'.

Utilizando dados do espanhol do período entre séculos XIII a XVII, García (1993) mostra que a MDO foi se expandindo gradualmente para os atuais contextos de uso. Os resultados de Company (2003) vão na mesma direção que os de García. Segundo Company, no espanhol medieval (século XIII-XV), pronomes pessoais e nomes próprios eram sistematicamente marcados. Os DPs humanos, que nesse período representavam um contexto pouco marcado, só se tornam frequentemente marcados a partir do século XVI.

García (1993) defende que a marcação de "a" e sua ausência não são equivalentes. A autora afirma que é bastante difundido que, na diacronia do espanhol, a MDO era um recurso de foco que levava a uma interpretação específica do referente do objeto. Isso explica por que, na diacronia da língua, nomes próprios são mais marcados que outros nomes, assim como, os singulares mais marcados que os plurais e os DP definidos mais que os indefinidos. Os dados da autora indicam também que os contextos de marcação diferencial não estavam totalmente definidos no início do século XVII, pois a preposição não era marcada diante de palavras que iniciadas por /a/.

Laca (2006) mostra o comportamento de objetos humanos indefinidos na diacronia do espanhol. Até o século XVIII, pode ser observado um aumento com objetos dessa natureza, contudo, no século XIX há uma queda na frequência. Por outro lado, com humanos definidos há um aumento contínuo. Como ressalta García (2018), no espanhol antigo, objetos humanos definidos eram marcados apenas quando deslocados da posição de argumento de $\mathrm{V}$, já no espanhol moderno, a marcação desses objetos é obrigatória independentemente da posição que ocupam. 
Após a exposição dos pontos teóricos relevantes para a discussão desse trabalho, apresentamos abaixo, na seção 5, nossos resultados sobre a presença da MDO no português antigo.

\section{A MARCAÇÃO DIFERENCIAL DE OBJETO NOS DADOS DE PORTUGUÊS ANTIGO}

\subsection{OS CORPORA UTILIZADOS}

O objetivo deste estudo é investigar a hipótese apresentada acima sobre o aumento da frequência dos casos de MDO no século XVII, isto é, se as ocorrências do fenômeno foram afetadas pelo contato do português com a gramática espanhola durante a existência da União Ibérica. Para investigar essa hipótese foram analisados textos de autores portugueses do período que compreende os séculos XVI a XIX. Os dados foram coletados em dois corpora: o Corpus Histórico do Português Tycho Brahe (doravante CTB), vinculado à Universidade Estadual de Campinas (GALVES; FARIA, 2010)' e o Post Scriptum (doravante PS), vinculado à Universidade de Lisboa (CLUL, 2014)2.

O primeiro corpus é formado por textos de diferentes gêneros, já o segundo corpus é constituído apenas por cartas. Além disso, os dois corpora têm um fator em comum: ambos utilizam o mesmo o mesmo sistema de anotação sintática ${ }^{3}$, ou seja, os dois corpora apresentam a análise sintática de todos os textos, empregando um sistema de anotação unificado.

No momento da consulta, o CTB era formado por 76 textos (3.303.196 palavras) em português de escritores nascidos entre os anos 1380 e 1881. Nele havia 44 textos anotados morfologicamente (o que corresponde a 1.956 .460 palavras) e 20 textos anotados sintaticamente (correspondente a 877.247 palavras) ${ }^{4}$.

O PS é constituído por aproximadamente 7 mil cartas privadas portuguesas e espanholas dos séculos XVI ao XIX escritas por pessoas de diferentes classes sociais e mantidas como provas em processos judiciais civis e eclesiásticos. As cartas são disponibilizadas no corpus em dois formatos: edição crítica digital e linguisticamente anotada, que se divide, ainda, em anotação morfossintática e sintática.

1 O Corpus Histórico do Português Tycho Brahe está disponível no link: <http://www.tycho.iel.unicamp.br/ tycho/corpus>

2 O corpus Post Scriptum está disponível no link: <http://ps.clul.ul.pt/pt/index.php?action=home>.

3 O sistema de anotação utilizado nos dois corpora foi adaptado do sistema originalmente criado para os Penn Parsed Corpora of Historical English, disponível em: <http://www.ling.upenn.edu/hist-corpora/annotation/index.htm>.

4 A coleta de dados foi realizada entre 2016 e 2017. Atualmente o Corpus Histórico do Português Tycho Brahe sofreu alterações e estão disponíveis 76 textos (3.302.666 palavras), sendo que 45 textos possuem anotação morfológica (2.012.768 palavras) e 27 estão anotados sintaticamente (1.234.323 palavras). 


\subsection{A METODOLOGIA UTILIZADA NA COLETA E NA ANÁLISE DOS DADOS}

Para a realização deste estudo, foram recolhidos, em corpora de textos históricos, dados de português europeu do período que compreende os séculos XVI a XIX. No CTB, foram selecionados cinco textos dos séculos XVI a XVIII, para cada século foram analisadas em torno de 200 mil palavras. Com relação aos dados do século XIX, analisamos dados de dois textos presentes no CTB e 174 cartas do PS. Como no primeiro corpus a quantidade de textos do século XIX era menor que os outros séculos, decidiu-se pela análise das cartas do PS.

No CTB, foram selecionados textos anotados sintaticamente e morfologicamente. Nos textos que possuíam o primeiro tipo de anotação, foi realizada uma busca eletrônica com a ferramenta Corpus Search 5 . Como a ferramenta citada realiza buscas apenas em arquivos anotados sintaticamente, nos textos anotados morfologicamente não foi possível utilizá-la. Desse modo, sem o auxílio de nenhuma ferramenta de buscas eletrônicas, procuramos nos textos casos em que a preposição "a" antecedia um objeto direto.

Nos textos do PS, foram encontrados 9 dados encabeçados pela etiqueta PP-ACC 6 , entretanto 2 casos eram ocorrências com a preposição "de", decidimos, portanto, expandir a busca e, sem a utilização do Corpus Search, foram encontrados 28 dados de objetos marcados pela preposição "a".

Dois tipos de dados foram selecionados: (i) objeto direto marcado por "a" e (ii) objeto direto não marcado. No CTB, coletamos os dois tipos de dados, e no PS coletamos apenas os dados de objeto direto marcado.

Os dados do segundo tipo foram selecionados para a análise da variação da MDO, ou seja, casos em que o objeto direto não é marcado pela preposição. Para isso, levantamos todos os verbos que ocorreram com os casos de MDO coletados ${ }^{7}$ e selecionamos apenas os verbos que tinham 5 ocorrências no conjunto total de dados recolhidos. Como analisamos dados do período que compreende 4 séculos, consideramos que o número 5 ilustraria os verbos que ocorreram mais de uma vez em cada século. Optamos por analisar a variação apenas nos séculos XVI e XVII.

Os verbos selecionados para a análise dos casos em variação foram: abranger, adorar, alcançar, amar, buscar, comer, destruir, julgar, mandar, matar, ofender, persuadir, preceder, prender, pretender e socorrer. Depois da seleção dos verbos, buscamos nos 10 textos representantes dos séculos XVI e XVII todas as ocorrências de objeto direto com os verbos selecionados.

\footnotetext{
5 A ferramenta Corpus Search é disponibilizada no link: <http://www.tycho.iel.unicamp.br/ tycho/apps/>.

6 Nos corpora selecionados, a etiqueta PP-ACC é utilizada para indicar casos em que um objeto direto é antecedido por uma preposição.

7 Nesta análise foram excluídos todos os objetos selecionados por verbos que regem a preposição "a”. Para a tomada dessa decisão foi consultado o levantamento de Araújo Adriano (Em andamento) sobre verbos que regem "a" no português.
} 
Estudos mostram que, no português, a MDO sofreu uma queda no século XVIII (GIBRAIL, 2003; DÖHLA, 2014; PIRES, 2017). Nossa opção por analisar apenas os casos de variação desses dois séculos nos leva a um quadro mais amplo das características das ocorrências do fenômeno no período em que houve o pico de frequências da MDO. A seguir, apresentamos alguns exemplos dos casos de variação analisados:

(14) a. E todos estavam com os olhos postos no Oriente, e com os joelhos em terra, adorando ao sol que nascia (CTB, v_004, século XVII).

b. A [seita] dos Fonccenxum: êstes adoram o Sol (CTB, C_007, século XVI).

(15) a. Muitas Nações comem a seus mortos (CTB, b_001, século XVII). $\mathrm{XVI})$.

b. Diz mais, que comiam carne humana os naturaes de Zipango (CTB, c_007, século

A seguir, apresentaremos os resultados que obtivemos na análise dos fatores nos dados coletados.

\subsection{OS RESULTADOS DA ANÁLISE DOS DADOS}

No total foram analisados 1231 dados, sendo 519 de MDO e 712 de objetos não marcados. Nos casos de variação foram considerados 826 dados, sendo 114 de MDO somados aos 712 de objeto não marcados.

A figura 1 a seguir mostra a frequência de ocorrência da MDO em cada século nos dados analisados. Fica evidente o pico de frequência do fenômeno nos séculos XVI e XVII, assim como a diminuição brusca no século XVIII, o primeiro século depois do fim da União da Ibérica. Esse resultado pode ser um indicativo da confirmação da hipótese aqui analisada: os casos de MDO no português europeu foram influenciados pelo contato com a gramática do espanhol. 


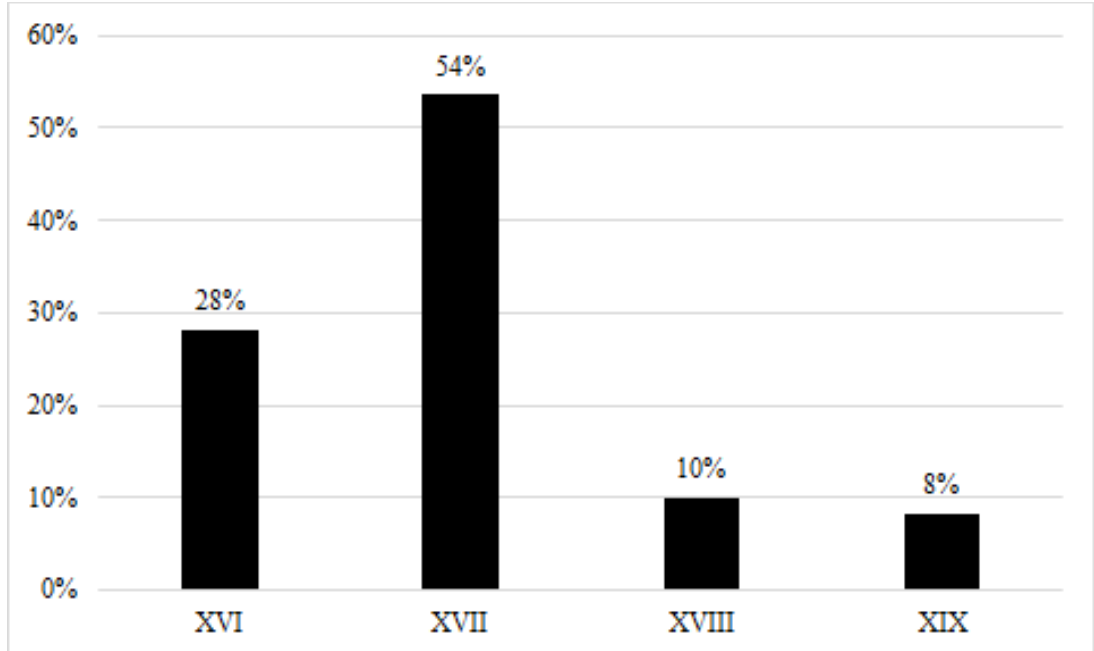

Figura 1. A frequência dos casos de MDO em cada século analisado.

A tabela abaixo mostra a quantidade de casos de MDO encontrados em cada século. Nela fica, novamente, evidente o pico de frequência do fenômeno nos séculos XVI e XVII, sendo que este último tem o maior número de dados. Ainda de acordo com a tabela, o século XVIII, que teve a maior quantidade de palavras analisadas, apresenta a menor porcentagem dos casos de MDO; neste século se observa também a diminuição da frequência do fenômeno. Considerando a quantidade de palavras analisadas e a quantidade de casos de MDO encontrados, é possível interpretar que o fenômeno em questão era, de modo geral, pouco frequente no português, pois mesmo nos séculos em que havia mais influência do espanhol, as ocorrências nas palavras analisadas não chegam a $2 \%$.

\begin{tabular}{cccc}
\hline Século & Dados de MDO & Quantidade de palavras & Relação entre dados e palavras \\
\hline XVI & 146 & 200.954 & $0,07 \%$ \\
XVII & 278 & 207.856 & $0,13 \%$ \\
XVIII & 52 & 229.033 & $0,02 \%$ \\
XIX & 43 & 128.253 & $0,03 \%$ \\
Total & 519 dados & 766.096 palavras & $0,07 \%$ \\
\hline
\end{tabular}

Tabela 1. Relação entre a quantidade de dados e a de palavras analisadas em cada século.

Em cada dado selecionado, analisamos os traços semânticos da animacidade, definitude e especificidade. Optamos por analisar tais traços, pois a literatura da área aponta que eles desencadeiam o uso da preposição "a" com o objeto direto. Na sequência, apresentamos os resultados dos fatores selecionados, começando pela animacidade. 


\subsubsection{A ANIMACIDADE NOS DADOS}

Como dito acima, adotamos a hierarquia da animacidade proposta por Cyrino (2018). Logo, distinguimos os objetos entre animados e inanimados, e a distinção entre humanos não foi feita. A seguir, são apresentados os resultados obtidos na análise dos casos de MDO do período que compreende os séculos XVI a XIX.

\begin{tabular}{ccccccc}
\hline & [+animado] & $\%$ & [-animado] & $\%$ & Total & $\%$ \\
\hline XVI & 120 & 82 & 26 & 18 & 146 & 100 \\
XVII & 243 & 87 & 35 & 13 & 278 & 100 \\
XVIII & 49 & 94 & 3 & 6 & 52 & 100 \\
XIX & 41 & 95 & 2 & 5 & 43 & 100 \\
Total & 453 & 87 & 66 & 13 & 519 & 100 \\
\hline
\end{tabular}

Tabela 2. A animacidade nos casos de MDO em cada século.

A tabela 2 mostra que o traço [+animado] tem uma alta frequência nos objetos marcados. A menor frequência de objetos desse tipo é observada no século XVI, já nos séculos posteriores, é registrado o aumento contínuo desses casos. Em oposição, a frequência dos inanimados marcados diminui ao longo dos séculos.

O comportamento do traço da animacidade observado nesses quatro séculos está de acordo com o esperado pela literatura: a marcação da preposição ocorre apenas com objetos animados. A seguir, são apresentados os resultados da presença da animacidade nos casos de variação da MDO.

\begin{tabular}{ccccccc}
\hline & MDO & $\%$ & Obj Dir & $\%$ & Total & $\%$ \\
\hline [+animado] & 37 & 15 & 214 & 85 & 251 & 100 \\
[-animado] & 7 & 3 & 194 & 97 & 201 & 100 \\
Total & 44 & 10 & 408 & 90 & 452 & 100 \\
\hline
\end{tabular}

Tabela 3. A animacidade nos casos de variação do século XVI.

\begin{tabular}{ccccccc}
\hline & MDO & $\%$ & Obj Dir & $\%$ & Total & $\%$ \\
\hline [+animado] & 55 & 32 & 118 & 68 & 173 & 100 \\
[-animado] & 15 & 7 & 186 & 93 & 201 & 100 \\
Total & 70 & 19 & 304 & 81 & 374 & 100 \\
\hline
\end{tabular}

Tabela 4. A animacidade nos casos de variação do século XVII.

As tabelas 3 e 4 acima revelam que, nos dois séculos, com o traço [+animado], são mais frequentes objetos não marcados: no século XVI, 85\% dos objetos animados não foram marcados, valor que cai para $68 \%$ no século seguinte. Já os casos de inanimados mostram que este é um contexto mais favorável à ausência da marcação.

Os resultados indicam que a presença positiva da animacidade favorece a marcação da preposição "a", enquanto a presença negativa não o faz, pelo contrário, sintagmas 
inanimados são majoritariamente instâncias de objetos não marcados. Na sequência, apresentamos os resultados da análise da presença da definitude nos dados coletados.

\subsubsection{A DEFINITUDE NOS DADOS}

Consideramos como sintagmas definidos aqueles que pressupõe a existência de uma referência fixa, como explicamos com mais vagar na seção 2.1. A seguir, são apresentados os resultados obtidos na análise da presença da definitude nos casos de MDO do período que compreende os séculos XVI a XIX.

\begin{tabular}{ccccccc}
\hline & [+definido] & $\%$ & [-definido] & $\%$ & Total & $\%$ \\
\hline XVI & 132 & 90 & 14 & 10 & 146 & 100 \\
XVII & 243 & 87 & 35 & 13 & 278 & 100 \\
XVIII & 47 & 90 & 5 & 10 & 52 & 100 \\
XIX & 40 & 93 & 3 & 7 & 43 & 100 \\
Total & 462 & 89 & 57 & 11 & 519 & 100 \\
\hline
\end{tabular}

Tabela 5. A definitude nos casos de MDO em cada século.

A tabela 5 acima revela que o traço [+definido] tem uma alta frequência nos casos de MDO. Em todos os séculos, a presença positiva desse traço se mantém em torno de $90 \%$. Além disso, os casos de indefinidos marcados, depois de um aumento do século XVI para o XVII, diminuem. Esse resultado, somado ao resultado da presença da animacidade nos casos de MDO (apresentado na tabela 2), pode indicar a evolução do fenômeno no português: apesar da diminuição na frequência de ocorrência, a tendência na língua é que a preposição seja marcada apenas em objetos [+animados] e [+definidos]. Abaixo são apresentados os resultados da presença da definitude nos casos de variação do fenômeno nos séculos XVI e XVII.

\begin{tabular}{ccccccc}
\hline & MDO & $\%$ & Obj Dir & $\%$ & Total & $\%$ \\
\hline [+definido] & 37 & 13 & 248 & 87 & 285 & 100 \\
[-definido] & 7 & 4 & 160 & 96 & 167 & 100 \\
Total & 44 & 10 & 408 & 90 & 452 & 100 \\
\hline
\end{tabular}

Tabela 6. A definitude nos casos de variação do século XVI. 


\begin{tabular}{cccccccc}
\hline & MDO & $\%$ & Obj Dir & $\%$ & Total & $\%$ \\
\hline [+definido $]$ & 65 & 22 & 227 & 78 & 173 & 100 \\
[-definido] & 5 & 6 & 77 & 94 & 201 & 100 \\
Total & 70 & 19 & 304 & 81 & 374 & 100 \\
\hline Tabela 7. A definitude nos casos de variação do século XVII.
\end{tabular}

De acordo com as tabelas 6 e 7, nos dois séculos, o traço [+definido] é mais frequente em objetos não marcados: $87 \%$ dos objetos definidos, no século XVI, não foram marcados, valor que cai para $78 \%$ no século seguinte. Com indefinidos é quase categórica a ausência da marcação: $96 \%$ dos casos de indefinidos não foram marcados no século XVI e no século posterior, o valor sofre uma ligeira queda para $94 \%$. Além disso, a frequência da presença positiva da definitude nos casos de MDO passou por um aumento: de $13 \%$ no século XVI para $22 \%$ no século XVII.

Os resultados das duas tabelas vão na mesma direção que os resultados da presença da animacidade no mesmo contexto, pois indicam que a presença negativa do traço semântico da definitude favorece a ausência da marcação da preposição "a".

A seguir, são apresentados os resultados da análise da presença da especificidade nos dados coletados.

\subsubsection{A ESPECIFICIDADE NOS DADOS}

Na análise da presença da especificidade nos dados selecionados, adotamos Farkas e Brasoveanu (2013), que defendem que os DPs específicos são aqueles que não apresentam variabilidade na referência, ou seja, denotam um referente único. Na sequência, os resultados da presença da especificidade em objetos marcados são apresentados.

\begin{tabular}{ccccccc}
\hline & [+específico] & $\%$ & {$[$-específico] } & $\%$ & Total & $\%$ \\
\hline XVI & 121 & 83 & 25 & 17 & 146 & 100 \\
XVII & 194 & 70 & 84 & 30 & 278 & 100 \\
XVIII & 43 & 83 & 9 & 17 & 52 & 100 \\
XIX & 40 & 93 & 3 & 7 & 43 & 100 \\
Total & 398 & 77 & 121 & 23 & 519 & 100 \\
\hline
\end{tabular}

Tabela 8. A especificidade nos casos de MDO em cada século.

Segundo os dados da tabela acima, o traço [+específico] apresenta uma alta frequência nos casos de objetos marcados diferencialmente. Contudo, a comparação com os 
resultados da presença positiva da animacidade e da definitude nos casos de MDO mostra que, nos séculos XVII e XVIII, a especificidade apresenta os menores valores, $70 \%$ e 83\%, respectivamente, contra $87 \%$ da animacidade e da definitude no século XVII, e, no século posterior, $94 \%$ da animacidade e $90 \%$ da definitude.

O aumento nos casos de objetos não específicos marcados que ocorre no século XVII e a diminuição no século posterior acompanham os casos de indefinidos marcados no mesmo período. A tabela 8 pode levar à afirmação que, dentre os traços aqui analisados, a especificidade desempenha um papel ligeiramente menor que os outros dois no desencadeamento da marcação da preposição. De maneira geral, os resultados dessa tabela somados aos resultados da animacidade e da definitude indicam que a tendência no português é que a MDO ocorra com objetos em que os três traços semânticos têm presença positiva. Na sequência, são apresentados os resultados do traço da especificidade nos casos de variação do fenômeno nos séculos XVI e XVII.

\begin{tabular}{ccccccc}
\hline & MDO & $\%$ & Obj Dir & $\%$ & Total & $\%$ \\
\hline [+específico $]$ & 31 & 13 & 210 & 87 & 241 & 100 \\
[-específico] & 13 & 6 & 198 & 94 & 211 & 100 \\
Total & 44 & 10 & 408 & 90 & 452 & 100 \\
\hline
\end{tabular}

Tabela 9. A especificidade nos casos de variação do século XVI.

\begin{tabular}{ccccccc}
\hline & MDO & $\%$ & Obj Dir & $\%$ & Total & $\%$ \\
\hline [+específico] & 46 & 20 & 184 & 80 & 230 & 100 \\
& & & & & & \\
[-específico] & 24 & 17 & 120 & 83 & 144 & 100 \\
Total & 70 & 19 & 304 & 81 & 374 & 100 \\
\hline
\end{tabular}

Tabela 10. A especificidade nos casos de variação do século XVII.

As tabelas 9 e 10 acima mostram, no século XVII, um aumento dos casos de MDO com objetos [+específicos]. Entretanto, pode-se perceber ainda uma elevação nos casos de [específicos] marcados. Esse aumento também é verificado na animacidade e na definitude, contudo, a especificidade detém o maior aumento, $11 \%$. Essa propriedade pode reforçar o que foi dito acima sobre a tabela 8 , a especificidade desempenha um papel menor que os outros traços na marcação, ou pode ainda ser uma indicação da influência espanhola no desenvolvimento do fenômeno no português: houve o aumento da frequência, mas as características ainda não estavam estabilizadas. 
De maneira geral, as tabelas 9 e 10 acima revelam que a presença positiva do traço da especificidade favorece os casos típicos de objeto direto. Por outro lado, com o traço [-específico] a marcação da preposição também é evitada. Isso indica que, assim como acontece com os resultados da animacidade e da definitude, a presença positiva do traço semântico não determina a MDO, entretanto a presença negativa é evitada nas ocorrências fenômeno.

\section{CONSIDERAÇÕES FINAIS}

Neste estudo, foi investigada a hipótese de que a frequência dos casos de MDO na história do português foi influenciada pelo contato com a gramática do espanhol durante a existência da União lbérica (1580-1640). A análise das ocorrências do fenômeno indicou o pico de frequência no século XVII e a diminuição brusca no século XVIII. Além disso, esses resultados mostraram que a MDO, mesmo no século XVII, era um fenômeno marginal na língua, se registrando a poucos casos.

Os resultados sobre a presença dos traços semânticos da animacidade, definitude e especificidade indicam que a presença positiva dos traços desencadeia a marcação diferencial. Contudo, os casos de variação mostraram que, mesmo com a presença positiva, a forma sem marcação é preferível. Entretanto, nos dados do século XVII há um aumento pela escolha da forma marcada com a presença positiva dos traços, principalmente com o da animacidade. Desse modo, a hipótese inicial é confirmada com ressalvas, pois os casos de objetos diretos não marcados são mais frequentes mesmo nos períodos de maior influência espanhola.

O estudo aqui apresentado tem, entretanto, limitações. Os resultados da análise da presença de traços semânticos podem, na verdade, ser reflexo de outros fatores, como, por exemplo, a natureza do objeto marcado. Ainda, dentre os fatores não considerados que podem ter influência sobre os resultados estão o gênero dos textos analisados e o contato dos autores com a língua espanhola.

Apesar das limitações apontadas, este trabalho contribui para um tema até o momento pouco investigado, a influência do espanhol na história do português. Ademais, há ainda poucos estudos sobre a MDO no português, principalmente que investiguem a influência dos traços semânticos na marcação diferencial.

Resta ainda investigar se a combinação dos traços semânticos com outros fatores favorece a marcação diferencial, como, por exemplo, a natureza dos objetos marcados diferencialmente e o contexto sintático da MDO. Além disso, são necessários estudos que investiguem os casos do fenômeno em períodos anteriores ao século XVI para que se verifique o comportamento dos fatores aqui analisados. 


\section{AGRADECIMENTOS}

Agradeço à Alba Gibrail pela leitura atenta de Pires (2017) e sugestões no tratamento dos dados, à Sonia Cyrino pelos comentários nas diferentes versões deste trabalho e aos pareceristas Marco Antonio Rocha Martins e Jorge Viana de Moraes pela leitura atenta e sugestões. Agradeço também ao CNPq pelo financiamento dessa pesquisa (Processo 142461/2019-9).

\section{REFERÊNCIAS}

AISSEN, Judith. Differential Object Marking: Iconicity vs. Economy. Natural Language \& Linguistic Theory, v. 21 , n. 3, p. 435-483, ago. 2003

ARAÚJO ADRIANO, Paulo A. Sobre a regência verbal da preposição 'a' no português brasileiro, Unicamp. Em andamento.

BOSSONG, Georg. Animacy and markedness in universal grammar. Glossologia: A Greek annual for general and historical linguistics, v. 2, n. 3, p.7-20, 1983

Differential Object Marking in Romance and Beyond. In: WANNER, Dieter; KIIBBEE, Douglas. New Analyses in Romance Linguistics. John Benjamins Publishing Company, 1991, p. 143-170.

BRASOVEANU, Adrian; FARKAS, Donka. Indefinites. In: ALONI, Maria; DEKKER, Paul. The Cambridge Handbook of Formal Semantics. Cambridge: Cambridge University Press, 2016, p. 238-266

CLUL (Ed.). P.S. Post Scriptum. Arquivo Digital de Escrita Quotidiana em Portugal e Espanha na Época Moderna. 2014. Disponível em: <http://ps.clul.ul.pt>. Acesso em: 6 fev.2017.

COMPANY, Concepción. Transitivity and Grammaticalization of Object. The diachronic struggle of direct and indirect object in Spanish. In: FIORENTINO, Giuliana. Romance Objects: Transitivity in Romance Languages. Berlin: Mouton de Gruyter, 2003, p. 217-260.

COPPOCK, Elizabeth; BEAVER, David. Definiteness and determinacy. Linguistics and philosophy, v. 38, n. 5, p. 377-435, 2015

CYRINO, Sonia. Reflexões sobre a marcação morfológica do objeto direto por A em português brasileiro. Estudos Linguísticos e Literários, Salvador, n. 58, p.83-103, 2017.

CYRINO, Sonia; ORDOÑEZ, Francisco. On the similarities and differences between null objects and DOM in BP and Spanish. Trabalho apresentado no Workshop Romania Nova VIII, Buenos Aires, Museu del Libro y de la Lengua, de 23 a 25 de novembro de 2016.

DÖHLA, Hans-Jörg. Diachronic convergence and divergence in differential object marking between Spanish and Portuguese. In: BRAUNMÜLLER, Kurt; HÖDER, Steffen; KÜHL, Karoline. Stability and Divergence in Language Contact: Factors and Mechanisms. Amsterdã: John Benjamins, 2014. p. 265-289.

ESCANDELL-VIDAL, Victoria. Differential object marking and topicality: The case of Balearic Catalan. Studies in language, v. 33, n. 4, p. 832-885, 2009.

FARKAS, Donka. Specificity distinctions. Journal of semantics, v. 19, n. 3, p. 213-243, 2002.

FARKAS, Donka; BRASOVEANU, Adrian. A typology of specificity. Revue roumaine de linguistique, v. 58, n. 4, p 355-369, 2013 
GALVES, Charlotte; FARIA, Pablo. Corpus Histórico do Português Tycho Brahe. 2010. Disponível em: <http://www.tycho.iel.unicamp.br/ tycho/corpus/en/index.html>. Acesso em: 6 fev. 2017.

GARCÍA, Erica. Syntactic diffusion and the irreversibility of linguistic change: personal $a$ in Old panish. In: SCHMIDT-RADEFELTD, Jürgen; HARDER, Andreas. Sprachwandel und Sprachgeschichte. Tübingen: Narr. p. 33-50, 1993.

GARCÍA, Marco. Nominal and verbal parameters in the diachrony of differential object marking in Spanish. Diachrony of differential argument marking, v. 19, p. 209, 2018.

GIBRAIL, Alba. O acusativo preposicionado do português clássico: uma abordagem diacrônica e teórica, 2003. 210 p. Dissertação (Mestrado em Linguística) - Instituto de Estudos da Linguagem, Universidade Estadual de Campinas, Campinas, 2003

HILLS, Elijah Clarence. The Accusative "A". Hispania, v. 3, n. 4, p. 216-222, 1920.

IEMMOLO, Giorgio. Topicality and differential object marking Evidence from Romance and Beyond. Studies in Language, v. 34, n. 2, p. 239-272, 2010.

LACA, Brenda. El objeto directo. La marcación preposicional. In: Sintaxis histórica de la lengua española. México: Fondo de Cultura Económica, 2006. p. 423-475.

MARDALE, Alexandru. Differential Object Marking in the First Original Romanian Texts. Formal Approaches to DPs in Old Romanian. Proto View, 2015

PENSADO, Carmen. La creación del complemento directo prepositional y la flexión de los pronombres personales en las lenguas románicas. In: PENSADO, Carmen. El complemento directo preposicional. Madrid: Visor, 1995

PIRES, Aline Jéssica. A marcação diferencial de objeto no português: um estudo sintático-diacrônico. Recurso online (151 p.). Dissertação (Mestrado em Linguística) - Instituto de Estudos da Linguagem, Universidade Estadual de Campinas, Campinas, 2017. Disponível em:

<http://www.repositorio.unicamp.br/handle/REPOSIP/330382>.

RAMOS, Jânia. Marcação de caso e mudança sintática no português do Brasil: uma abordagem gerativa e variacionista, 1992. 380f. Tese (Doutorado em Linguística) - Instituto de Estudos da Linguagem, Universidade Estadual de Campinas, Campinas, 1992.

TEYSSIER, Paul. História da língua portuguesa. 3. ed. São Paulo, SP: Martins Fontes, 2007.

TORREGO, Esther. The dependencies of objects. Cambridge, MA: MIT, 1998.

El complemento directo preposicional. In: BOSQUE, Ignacio; DEMONTE, Violeta. Gramática descriptiva de la lengua española. Madrid: Espasa, 1999, p.1779-1805 